\title{
Quantitatively Analyzed Vegetation Coverage and Its Dynamic Changes of Mulan County in Heilongjiang Province Based on RS and GIS
}

\author{
Ying Zhou ${ }^{1}$, Jiaxing $\mathrm{Qu}^{1}$, \\ ${ }^{1}$ Heilongjiang Province National Defense Science and \\ Technology Institute, \\ Harbin, 150090, China
}

\author{
Juan $\mathrm{Wu}^{2}$, Fangping $\mathrm{Liu}^{2}$ \\ ${ }^{2}$ College of Hydraulic and Electrical Engineering, \\ Heilongjiang University, \\ Harbin, 150086, China
}

\begin{abstract}
Vegetation cover not only takes as an import parameter for monitoring the vegetation situation of land surface, but also is an important indicator indicates the quality of the ecological environment and its changes. Therefore, in this paper, The Landsat TM images of 1989 and 2011 was used to extract the normalized difference vegetation index (NDVI), then, the vegetation cover was obtained by NDVI using RS software ERDAS IMAGE 9.2, the results shown that : the increasing area of NDVI (0.2 0.3) was greatest, which was $141.41 \mathrm{~km}^{2}$, on the contrary, the reduced area of NDVI $(0.4 \sim 0.5)$ was $340.29 \mathrm{~km}^{2}$, the lower vegetation coverage region covered the greatest increasing area, while the reduced area of higher vegetation coverage was maximum.
\end{abstract}

Keywords-NDVI, RS; Vegetation cover; Mulan county

\section{INTRODUCTION}

Vegetation coverage, usually refers to a proportion or percentage that vertical projection of the vegetation canopy surface area accounting per unit area ${ }^{[1]}$, which not only is an important parameter characterization of a number of land surface vegetation ${ }^{[2]}$, but also is an important indicator indicates the quality of the ecological environment and its changes, meanwhile, it is the most sensitive on the topography, soils, hydrology, climate, and human activities $^{[3-4]}$. Therefore, it has important practical significance for the evaluation of regional ecological environment from vegetation cover change information by using RS and GIS technology ${ }^{[5-6]}$. In this paper, the Landsat TM images of 1989a and 2011a were taken as the main data resources, the normalized difference vegetation index (NDVI) was obtained from two images in Mulan county of Heilongjiang Province, on this basis, vegetation cover was extracted from NDVI and its characteristics was studied, which can provide certain theoretical basis to restore the ecological construction and environment management. It also provide the scientific basis for the maintaining of ecological environment, reasonable utilization of resources, and the study results can optimize allocation of ecological protection and sustainable utilization in Songhua River basin.

\section{STUDY AREA}

Mulan County is located at north shore of the middle reaches of the Songhua River, south-central of Heilongjiang Province, extending from $127^{\circ} 31^{\prime}$ to $128^{\circ} 18^{\prime} \mathrm{E}$, and from $45^{\circ} 54^{\prime}$ to $46^{\circ} 36^{\prime} \mathrm{N}$, with an area of $3600 \mathrm{~km}^{2}$. The north of
Mulan is mountainous, and the terrain has a north to south low trend. Rivers in it are anabranch of Songhua River, and the main rivers are Miranda River and Poplor River. Mulan features a monsoon-influenced, humid continental climate with annual average temperature $1 \sim-3^{\circ} \mathrm{C}$, and the extreme maximum temperature is $35.5^{\circ} \mathrm{C}$, the extreme minimum temperatures is $-42^{\circ} \mathrm{C}$. Annual average rainfall is $596.2 \mathrm{~mm}$ and frost-free period 127 is days. Mulan is very rich in natural resources with an area of 252 acres of forestland with mainly pine, oak, very, locust, poplar, elm , birch and other trees.

\section{DATA PROCESSING AND STUDY METHODS}

\section{A. Data Sources}

For the study area, we taken the images which were clear and has little cloud in August and September due to the good period the vegetation growth .We acquired two remote images taken by the Landsat TM5 senor of the study site dated September 1989 and August 2010 as the primary data source. The two images can well reflect the views of local vegetation cover and land use ${ }^{[7]}$. In addition, we collected current land use maps, topographic map (1:50,000)and some GPS survey data of study region.

\section{B. Processing of Remote Sensing Image Data}

Firstly, the topographical map was corrected by using the ground control points (GCPs) in ERDAS IMAGE9.2, then referenced to the correction topographical map. The geometric correction process of Landsat TM was carried out by used a first order polynomial equation with the project of Xian80 coordinate, with the methods of Quadratic polynomials interpolation and Double linear interpolation. And then the Positional root mean square error (RMSE) was kept below half of an pixel, then the atmospheric correction was performed by using by using the FLAASH module in remote sensing software ENVI, the Remote sensing image was masked by using the boundary of the study area

\section{Calculation of Vegetation Cover}

The calculation of vegetation cover in this study primarily based on the normalized difference vegetation index ${ }^{[8-9]}$. The NDVI is the normalized ratio of reflectance value at red and infrared part of the electromagnetic spectrum. NDVI is calculated as followed: 


$$
\mathrm{NDVI}=\frac{\mathrm{CH} 4-\mathrm{CH} 3}{\mathrm{CH} 4+\mathrm{CH} 3}
$$

where $\mathrm{CH} 4$ and $\mathrm{CH} 3$ are reflectance in the near infrared and the red bands, respectively. The NDVI values have been typically used to map spatial distributions of vegetation $^{[10]}$

The vegetation coverage of study region was obtained by using NDVI that was calculated with the support of Model module in ERDAS 9.2, which was as followed:

$$
f_{c}=\frac{N D V I-N D V I_{\min }}{N D V I_{\max }-N D V I_{\min }}
$$

Where NDVI is the normalized difference vegetation index; $N D V I_{\min }, N D V I_{\max }$ are normalized vegetation index the minimum and maximum values, $N D V I_{\min }$ corresponding areas are non-vegetation coverage, including bare ground and unused land. $N D V I_{\max }$ corresponding area mostly covered by vegetation, including forest and cropland .

\section{Vegetaion Cover Classification}

According to Standards classification and gradation of soil erosion enacted in $1996^{[11]}$, combining with ground field survey and soil erosion intensity data, the vegetation cover is divided into five levels ${ }^{[12]}$ as followed referencing to the existing literature of Water Resources: grade I ( waters ) : vegetation coverage 0; II level ( low vegetation coverage with vegetation cover range from 0.0 to 0.62 ): vegetation coverage $0-0.62$; mostly bare soil, low yield of grassland , shrub land , fallow land and residential land use ; Grade III ( medium vegetation with vegetation cover range from 0.62 to 0.82 ): $0.62-0.82$ vegetation coverage , mainly in high-yielding meadows, forestland and some cropland, are generally flaky or massive distribution ; grade IV ( high vegetation with vegetation cover range from 0.82 to 1 ); mostly jungle and good arable land, etc.,showing a sheet or block distribution. Complete classification of vegetation cover in the ArcGIS 9.2.

\section{RESUltS AND ANALYSIS}

\section{A. Statistical Analysis of NDVI}

With the support of ArcGIS, according to research needs, the NDVI is divided into seven categories, which is followed as, level 1 (NDVI $=-1)$, level $2(-1 \sim 0.1)$, level 3 $(0.1 \sim 0.2)$, level $4(0.2 \sim 0.3)$, level $5(0.3 \sim 0.4)$, level $6(0.4$ $\sim 0.5$ ), level 7 (NDVI $>0.5$ ) respectively. As it shown in table I, we know that the area proportion of NDVI accounted of lever 7 in the two-data is largest, respectively known as $49.95 \%$ and $54.10 \%$, followed by NDVI of level 6 . The area proportion of level 2 NDVI is minimum, $0.58 \%$ and $0.48 \%$ respectively. The area, when NDVI $=-1$, in 1989 was less $61.19 \mathrm{~km}^{2}$ than in 2011, where is mainly concentrated in the water body of the Songhua River region; the area of NDVI between 0.4 and 0.5 was reduced with $340.29 \mathrm{~km}^{2}$, which is maximum; the area of NDVI between -1 to 0.1 was reduced in minimum. Areas of NDVI in the range of $0.1 \sim 0.4$ and NDVI $>0.5$ are in a state of increasing, the NDVI of biggest increased area are between 0.2 and 0.3 ; NDVI in- $\sim 0.1$ and $0.4 \sim 0.5$ are in a reduced state, in which the area of NDVI between 0.4 to 0.5 reduced in maximum.

\begin{tabular}{|c|c|c|c|c|c|c|}
\hline \multirow[b]{2}{*}{ NDVI level } & \multicolumn{2}{|c|}{1989} & \multicolumn{2}{|c|}{2011} & \multicolumn{2}{|c|}{ Change } \\
\hline & Area $/ \mathrm{km}^{2}$ & $\begin{array}{c}\text { Percentage } \\
\% \\
\end{array}$ & Area $/ \mathrm{km}^{2}$ & $\begin{array}{c}\text { Percentage } \\
\%\end{array}$ & $\begin{array}{l}\text { The amount of } \\
\text { change } / \mathrm{km}^{2}\end{array}$ & $\begin{array}{c}\text { Percentage } \\
\%\end{array}$ \\
\hline 1 & 163.89 & 5.16 & 102.7 & 3.23 & -61.19 & -1.93 \\
\hline 3 & 28.4 & 0.89 & 59.56 & 1.87 & 31.16 & 0.98 \\
\hline 4 & 102.48 & 3.23 & 243.89 & 7.68 & 141.41 & 4.45 \\
\hline 5 & 356.91 & 11.23 & 458.79 & 14.44 & 101.88 & 3.21 \\
\hline 6 & 920.43 & 28.97 & 580.14 & 18.26 & -340.29 & -10.71 \\
\hline
\end{tabular}

Table I. Statistics in degree of change from 1989 to 2011

\section{B. Accuracy Evaluation of Vegetation Coverage}

This study chose random sampling method to test the accuracy of using NDVI for the quantitative inversion of vegetation coverage. Get samples in areas in four different levels of vegetation coverage, and then complete accuracy of the vegetation cover evaluation by using handheld GPS, error matrix analysis and field investigation on the sampling points. After analysis, the accuracy of various levels of vegetation coverage classification is more than $90 \%$. This result shows that the quantitative reverse NDVI vegetation coverage reflect the actual situation of the vegetation coverage in the study area.

\section{Change Trends of Vegetation Cover area}

Based on the remote sense process and quantitative inversion of research area over a period of 22 years(1989-2011), extracted vegetation are 4 types:water body, low vegetation coverage, medium vegetation coverage and high vegetation coverage. The statistics in table II shows: the area of the high vegetation coverage is largest.The main land types in the high vegetation coverage are high-density forestland and good cropland. Forestland occupied a large percent in the high vegetation coverage area, showing the distribution of patchy or block, which have ratios of $65.10 \%$ and $45.78 \%$ respectively. This vegetation coverage type has a higher proportion in the 
study area mainly because two remote sense data acquired at the time when plant was in luxuriant growth period. The area with a high degree of vegetation coverage constituted landscape in the study area reduced $614.13 \mathrm{~km}^{2}$ from 1989 to 2011. But the area with a high degree of vegetation coverage not formed landscape is $19.32 \%$. The area of water body are $159.75 \mathrm{~km}^{2}$ (1989)and $103 \mathrm{~km}^{2}$ (2011)respectively, which is the minimum in 4 types of vegetation. The vegetation of low coverage and medium coverage in the area tended to increasing, in which the low vegetation coverage increase largest, increased with 486.83 $\mathrm{km}^{2}$ from $123.17 \mathrm{~km}^{2}(1989)$ to $610 \mathrm{~km}^{2}(2011)$.. The area of the medium vegetation coverage increased $184.05 \mathrm{~km}^{2}$, and increasing ratio is $5.59 \%$.

Table II. Statistics of vegetation coverage and the degree changes from 1989 to 2011

\begin{tabular}{|c|c|c|c|c|c|c|}
\hline \multirow[b]{2}{*}{ NDVI level } & \multicolumn{2}{|c|}{1989} & \multicolumn{2}{|c|}{2011} & \multicolumn{2}{|c|}{ Change } \\
\hline & Area $/ \mathrm{km}^{2}$ & $\begin{array}{c}\text { Percentage } \\
\%\end{array}$ & Area $/ \mathrm{km}^{2}$ & $\begin{array}{l}\text { Percentage } \\
\%\end{array}$ & $\begin{array}{l}\text { The amount of } \\
\text { change } / \mathrm{km}^{2}\end{array}$ & $\begin{array}{c}\text { Percentage } \\
\%\end{array}$ \\
\hline 1 & 159.75 & 5.03 & 103 & 3.24 & -56.75 & -1.79 \\
\hline 2 & 123.17 & 3.88 & 610 & 19.20 & 486.83 & 15.32 \\
\hline 3 & 825.95 & 25.99 & 1010 & 31.78 & 184.05 & 5.79 \\
\hline 4 & 2068.76 & 65.10 & 1454.63 & 45.78 & -614.13 & -19.32 \\
\hline
\end{tabular}

\section{Spatial Change Characteristics of Vegetation}

Based on quantitative analysis of dynamic transition of the vegetation coverage areas with the support of ArcGIS, further analysis are done to reveal the dynamic variation and trends and the spatial evolution model. This will help us to grasp the overall development stage of the vegetation coverage in the study area. For the water body, the parts of mainly reduced are located in the mudflat wetland along the Songhua River. The main reasons for the reduction due to the influence of the weather and other natural conditions, but human disturbance along the Songhua River basin can not be overlooked. The beach land (wetlands) ---- cultivated land is the main track changes. In the land using process, parts of the wetlands along the river disappeared due to the irrational use of human, leading to the disappearance of the river surface deformation, some of the river segment narrowed and the water areas becomes smaller. The population in the high degree of vegetation cover area where now reduced is relatively dense. What be found in the field survey is that resident devastate forests for cropland. Driven by economic interests, unreasonable activities caused the transformation form forest land to cropland. In addition, partially dense forest degenerate into shrub land due to human influence. Low-altitude areas of vegetation increase mainly distributed in the agricultural zones and higher elevations of the mountainous region surround the city. For the mountain areas of high altitude, the source of increaseing areas are a number of fallow land and abandoned arable land (fallow land). Forestland dominated the evolution of the region's land-use patterns. Human activities has been limited due to the influence of topography and other natural conditions. This result in "Grain for Green” and "returning cropland to pasture " and other ecological projects implemented, and the "Grain for Green" and other projects in the study area gets some achievement. Areas with medium height of vegetation cover increased mainly located at the part of the forest area and the outskirts of the original vegetation cover in Mulan. This is mainly because the implementation of the "Grain for Green", "returning cropland to pasture" and other ecological policy. The former high coverage vegetation suffer the unreasonable interference caused by man, resulting in destruction of the particular high density of forestland, the density of vegetation types showed some degree of thinning and fragmentation increased and some forest change into cropland. With the Natural Forest Protection Project, "Grain for Green" and other ecological policies to cover vegetation, the study area vegetation coverage transite from low to high. This progress shows deteriorating of the ecological environment has relieved.

In a word, the vegetation coverage areas with low vegetation coverage (level II) and medium vegetation coverage (level III) in 2011 was increased by $15.32 \%$ and $5.79 \%$ than that in 1989 , respectively, the low vegetation coverage area (level II) increased maximum. The high vegetation coverage area and water body area less than 1989, in which the high vegetation coverage (level IV) decrease largest with $19.41 \%$

\section{CONCLUSIONS}

The areas of NDVI ranges from 0.1 to 0.4 and NDVI> 0.5 are in a increase state, and areas with a value of NDVI ranges from 0.2 to 0.3 increased maximum, the area of NDVI from -1 to 0.1 and from 0.4 to 0.5 are in a reduction state, in which the NDVI from 0.4 to 0.5 reduced maximum.

The vegetation coverage in the low vegetation coverage area and the medium vegetation coverage area in 2011 was large than 1989, and the low vegetation coverage area increased maximum; the high vegetation coverage area and water body area less than 1989, in which the high vegetation coverage decrease largest.

\section{CORRESPONDING AUTHOR}

Zhou Ying, senior engineer, Heilongjiang Province National Defense Science and Technology Institute. Email:zy@nstc.gov.cn. Mobile phone:13384519666. 


\section{REFERENCES}

[1] Purevdorj T, Tateishi R, Ishiyama T, et al. Relationships between percent vegetation cover and vegetation indices[J]. International Journal of Remote Sensing,1998,19 (18):3519-3535.

[2] ZHANG Yunxia, LI Xiaohing, CHEN Yun-hao.Overview of field and multi-scale remote, sensing measurement approaches to grassland vegetation coverage[J].Advance in EarthSciences,2003,18(1):85-93.

[3] Li F, Wang P, Wang J, et a l. Effect s of irrigation before sowing and plastic film mulching on yield and water uptake of spring $\mathrm{w}$ heat in semiarid Loess Plateau of China[J].Agricultural Water Management, 2004, 67(2):77-88.

[4] Deng fei,Quan zhanjun,Yu yunjiang, Study on the Vegetation Coverage Change and Its Impact Factors in Wulanmulun River Basin During the Recent 20 Years [J].Bulletin of Soil and Water Conservation,2011,18(3):137-141.

[5] MA Chao-fei,MA Jian-wen,Buhe-Aosaier.Quantitative Assessment of Vegetation Coverage Factor in LISLE Model Using Remote Sensing Data [J].Bulletin of Soil and Water Conservation, 2001,21( 4):6-9.

[6] Gao qingzhu,Duan minjie,Li yu'e.Change Trends of Grassland Coverage and Pasture Growth in the Northwest Area of Tibet
[J].Chinese Journal ofAgrometeorology,2010,31(4): 582-585.

[7] LI Miaomiao,WU Bingfang, YAN Changzhon, et al. Estimation of vegetation fracaion in the upper basin of Miyun reservoir by remote sensing[J]. Resources Science, 2004, 26(4): 153-159.

[8] Li xiao bin,Chen yunhao,Shi peijun,et al.Detecting Vegetation Fractional Coverage of Typical Steppe in Northern China Based on Multi-scale Remotely Sensed Data[J].Acia Boianica Sinica,2003,45(10):1146-1156.

[9] Gutman G,Ignatov A.The derivation of the green vegetation fraction from NOAA/AVHRR data for use in numerical weather prediction models[J]. International Journal of Remote Sensing,1998,19:1533-1543.

[10] Lu Zhongzheng,ZhangGuangchao,GaoHuijun,et al.Vegetation Coverage Changes Research in EastM aowusu Sand Area[J].Geo-Information Science,2001,12(4):42-44.

[11] GB/SL190-1996,Standards for classification and gradation of soil erosion[S].

[12] Gai Yongqin,Li Xiaobing,Zhang Li,et al.Land Use/ Cover Change and vegetation Courage Monitoring byRemote Sensing:A Case Study of Miyun, Beijing[J].Resources Science,2009, 31(3):523-529. 